\title{
Research on Practical Ability Cultivation of Undergraduates in Engineering in Universities
}

\author{
Hansong Yang \\ Huanghe Science and Technology College \\ Zhengzhou, China
}

\author{
Guangkun Sun \\ Huanghe Science and Technology College \\ Zhengzhou, China
}

\author{
Qin Zhang \\ Huanghe Science and Technology College \\ Zhengzhou, China
}

\begin{abstract}
To serve the society, regional economy development and socio-economic construction is the main purpose of cultivating talents in universities. In order to cultivate applied talents which satisfy the needs of society, characteristic talents are required to be cultivated. And because these characteristic talents should have certain professional competitiveness, practical and effective measures is needed to be taken in talents cultivation, so that students' practical ability can be strengthened on the basis of basic theories being mastered by them, the relationship between personal technical ability and the demand for talents due to social economy development can be dealt with, and applied talents satisfying social needs can be cultivated. To strengthen innovation talents cultivation and intensify students' innovation ability are of great theoretical and practical significance to talents cultivation in modern engineering specialty. This paper has put forward the significance of strengthening practical teaching, the relationship between practical teaching and ability cultivation, and practical teaching system construction, which plays an essential theoretical role in the research of engineering specialty.
\end{abstract}

Keywords-competitiveness; innovation talents cultivation; practical ability; practical teaching system

\section{INTRODUCTION}

In the wake of universal implementation of mass education, the gross enrollment rate of higher education has been more than $50 \%$. The critical issue of graduates cultivated by higher education is employment. Its competition is increasingly fierce in the mass implementation phase of higher education. One school and one specialty which want one way out, must have an absolute advantage in employment competition. While to win in employment competition, school and specialty must analyze talent needs of employers, namely, different employers in different developing stage will change their talent needs to some extent. This is a problem particularly worthy of universities' attention. Especially for civilian-run institutions, the standard of cultivating talents and the professional competence of students after graduation should be further studied.

\section{Why ENGINEERING SPECIALTY IN UNIVERSITIES SHOULD STRENGTHEN PRACTICAL ABILITY CULTIVATION}

Take talent needs of enterprises as example to analyze enterprises' talent demands. What kind of talent is needed by enterprises, which is important when universities is deciding talent cultivation goal. Through discussing enterprise talent construction mode, it is found that enterprise divides talents into ladder level such as top talent, senior talent, intermediate talent and basic talent, and to be higher in this ladder will have more professionalism, higher research level and competence but less people; to be lower in this ladder will have more generality. Thus, investigate in accordance with this classification, establish huge talent pool and allocate talent to a reasonable state. Based on a further analysis of some enterprises' talent structure, enterprises give more consideration on how to make rational use of talents during talent selection, which cannot be addressed by owning a group of highly educated people. How enterprises reasonably optimize and use talents with differing education background, professional title and ability is the essential aspect which enterprises' human resources should lay particular attention. Therefore, the enterprises' allocation of talents needs to be comprehensively considered in accordance with the actual situation. Enterprise talent structure is shown in "Fig. 1".

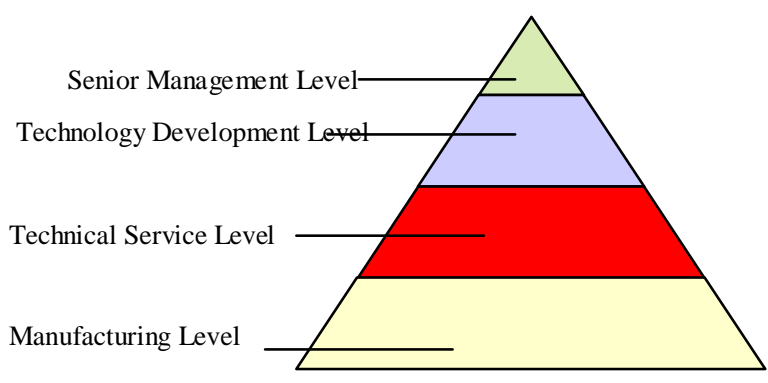

Fig. 1. Enterprise talent structure

Through research, it is discovered that, in this pyramid structure, the first level needs the least talent and the needed 
talents all have rich practical experience and good management ability, taking up $1 \%$ of the total talents. Personnel of first level usually are senior managers engaging in enterprise production management for many years. Personnel of second level are technology management and development, taking up $10 \%$ of the total talents. Technology development level needs talents with development and management ability, and has a high requirement for technology basis, basic theories and skills. This position usually is assumed by enterprise engineers who have manyyear producing practical experience. Therefore, the technical service level which has a large demand, a high technical requirement and mainly engages in site technical instruction works, takes up a larger proportion and needs applied special talents. Accordingly, this level always is the misunderstanding of talents cultivation. Undergraduate specialties in universities cultivate talents in accordance with elite education in theoretical research, while frontline production technician is main cultivation goal of specialty in junior college and technical schools. Hence, as for enterprises' talents demand, to strengthen talents cultivation in technical service is a direction for engineering specialty in universities. In order to achieve this, the talents cultivation mode and scheme should be adjusted by strengthening practical ability. After researching engineering specialty in many universities, the same conclusion is drawn, namely to ensure graduates who are cultivated by schools' specialties to have competiveness and ability of fast adapting to the posts, students' practical application ability cultivation must be strengthened for meeting the needs of social development.

\section{CONTENTS AND MEANING OF PRACTICAL TEACHING}

Practical teaching is an important part of professional cultivation program, and a vital way of theoretical knowledge transformation and ability cultivation. Students' practical ability is improved and so does their analyzing and problemsolving ability through practical teaching. Hence, strengthening professional practical teaching is of great significance in both theory and practice.
- Increase practical teaching consciousness and strengthen practical ability cultivation, so that make students deal with engineering problems faster.

- Intensify students' innovation ability so that be beneficial for displaying the students' independent innovation.

\section{RELATIONSHIP BETWEEN PRACTICAL TEACHING PROCEDURE AND ABILITY}

Specialty practical teaching procedure and specialty practical ability cultivation are inseparable. Professional ability cultivation cannot be separated from specialty practice teaching procedure, while various specialty practice teaching procedures point to different specialty abilities. There is an organic connection between them, being shown in "Fig. 2".

- Ability A: it mainly denotes the most basic ability that students acquire after graduation, namely mastering computer, foreign language, political accomplishment, daily communicative competence and other abilities. These abilities are general abilities in higher education whose cultivation relies on computer, and a large number of operations and use of corresponding software. Foreign language ability is exercised through reading, writing and communicating. Political accomplishment mainly relies on the understanding and application of policies. Daily communicative competence refers to the ability of communicating with people and dealing with interpersonal relationships, which can be cultivated through communication in four-year college life.

- Ability B: it majorly denotes physical ability, psychological quality and others. Its improvement is through admission military trainings, physical education curriculum and other courses. Meanwhile, corresponding procedures are set up to improve the cultivation.

- Make students further apply and understand the acquired basic knowledge and theories.

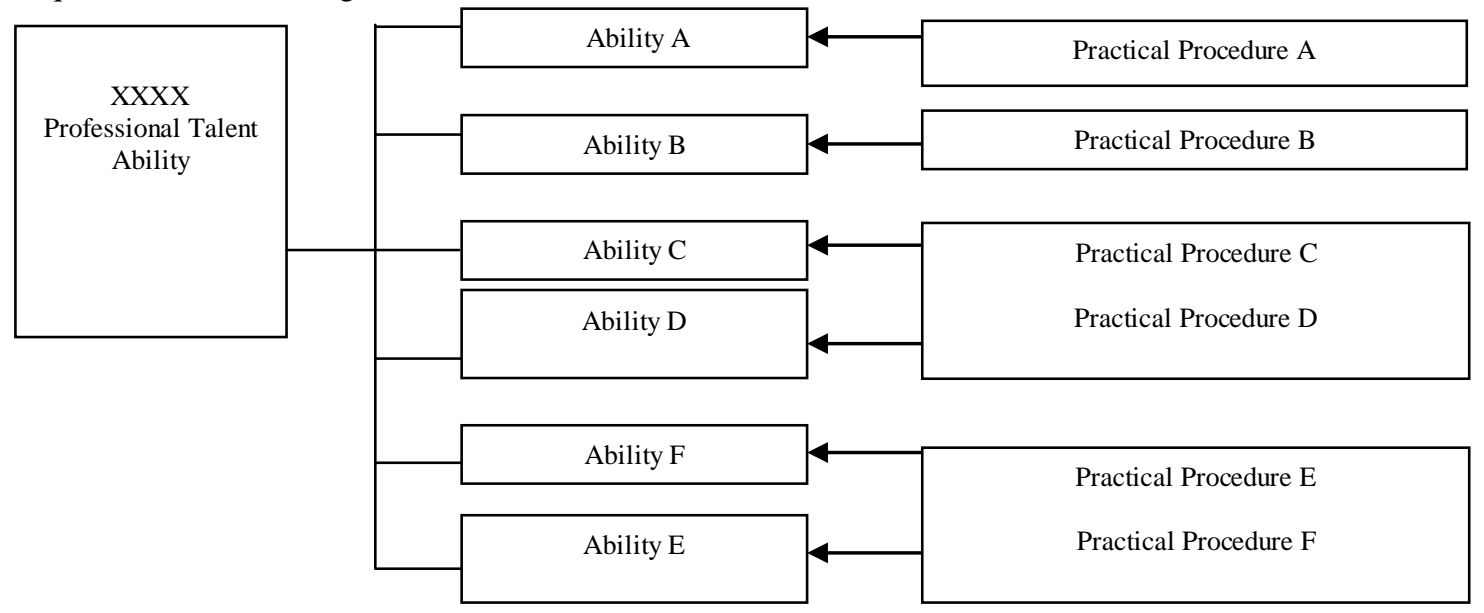

Fig. 2. Relationship between practical teaching procedure and ability 
- Ability C and ability D: These two abilities mostly refer to professional ability and ability for addressing and dealing with professional problems, which is the core problem and main problem to be solved of specialty. Students' professional ability differs due to different specialty. Therefore, the needed practical procedures have great difference, so does designed ability cultivation procedures according to different specialty. Based on specialty's characteristics, certain practical procedures and corresponding hours and proportion are arranged to ensure that students can achieve the basic ability required by specialty.

- Ability E and ability F: they mean innovation ability and other ability cultivation beyond professional ability. Namely, through professional learning, not only professional ability cultivation is acquired but

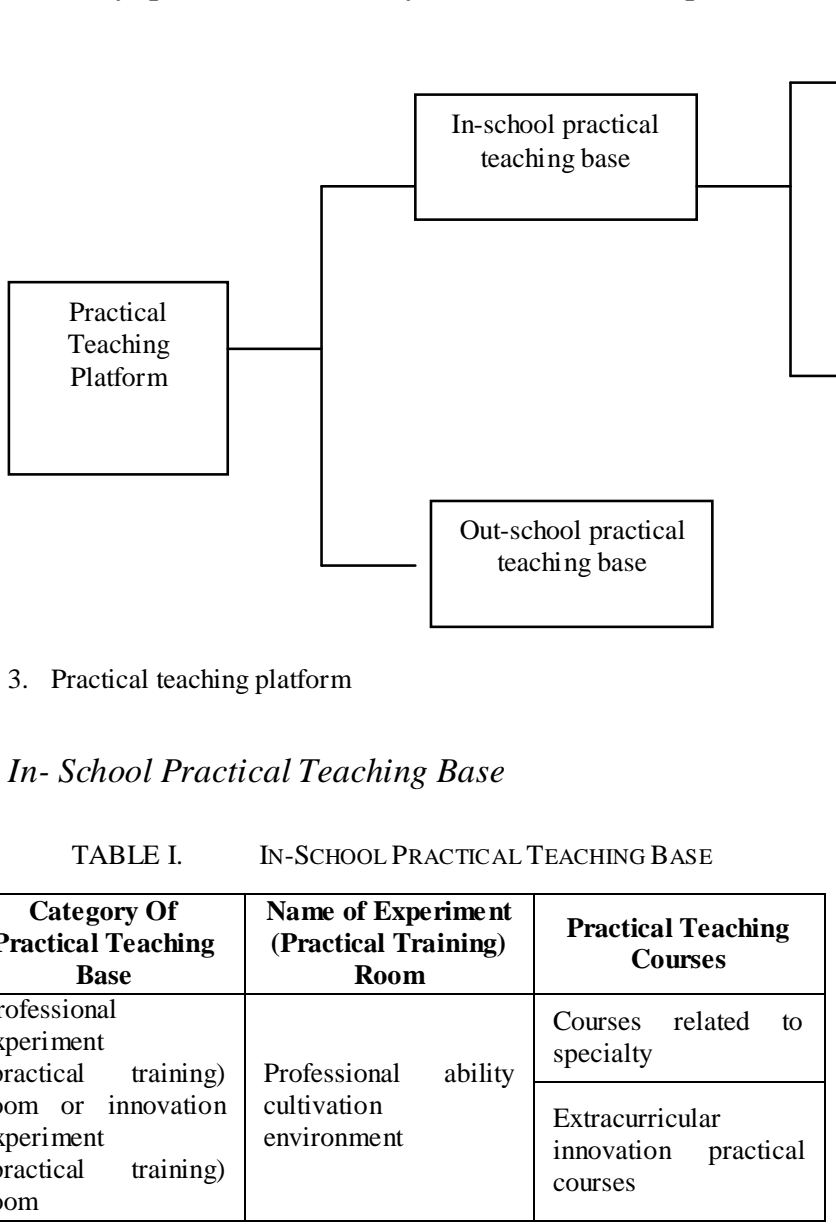

B. Out-School Practical Teaching Base

TABLE II. Out-School Practical Teaching Base

\begin{tabular}{|c|l|c|}
\hline \multicolumn{1}{|c|}{$\begin{array}{c}\text { Out School Enterprise } \\
\text { (Company) Name }\end{array}$} & Practice Content & $\begin{array}{c}\text { Accepted } \\
\text { Students }\end{array}$ \\
\hline $\begin{array}{l}\text { Out school professional } \\
\text { base }\end{array}$ & $\begin{array}{l}\text { Content related to } \\
\text { specialty }\end{array}$ & \\
\hline
\end{tabular}

also the cultivation of competitiveness, social survival ability, team cooperation ability, etc. The cultivation and training of this ability should be strengthened during practical teaching.

\section{Basic Composition of Practical Teaching PLATFORM}

Different ability cultivation needs certain practical teaching environment. Especially professional accomplishment and ability cultivation have stricter requirements for practical teaching environment. The basic structure of practical teaching environment is composed by the contents of "Fig. 3", "Table I" and "Table II".
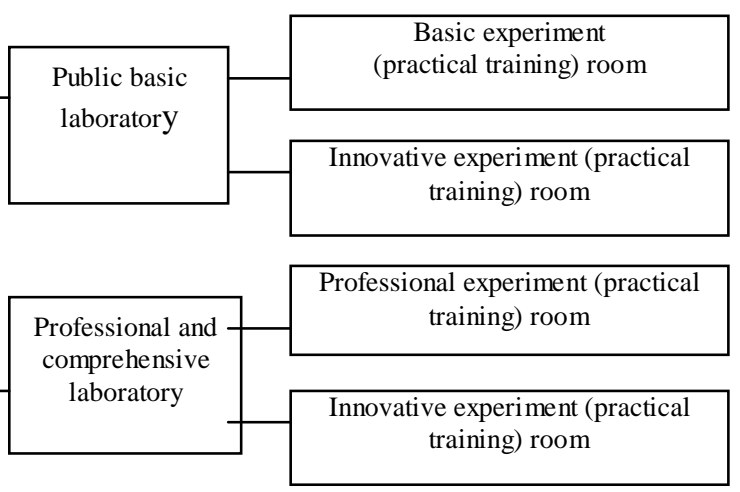

\section{Practice Teaching StafF SuPPort}

Teaching staff plays the main role in practical teaching procedure. Firstly, the number of practical teaching teachers should be sufficient. Secondly, practical teaching structure should be so reasonable that ensure structures of education background, study relationship and professional title to achieve a more rational composition. "Double-qualified teachers" should take up a higher proportion. Training of non doublequalified teachers should be strengthened. Only own a group of teaching staff with reasonable structure and stronger ability can ensure the successful going through of practical procedures.

\section{Construction of Practical Teaching System}

Professional practical teaching system is consisted of practical teaching procedure, practical teaching environment, practical teaching staff and practical teaching management. The practical teaching system is shown in "Fig. 4".

\section{ASSESSMENT OF PRACTICAL AbILITY}

The assessment of this part should take the test on skills and practical ability as main content. In other words, it is to assess whether students can deal with practical problems. 
Therefore, according to various specialties, the content and form of assessment are of great difference, but every assessment must evaluate students' ability in practical use and problem addressing.

How to construct assessment system? Different specialties should ensure the accuracy of assessment according to the basic requirements in cultivating applied talents of each specialty and the basic technological projects or technological achievements needed for completing specialty learning.

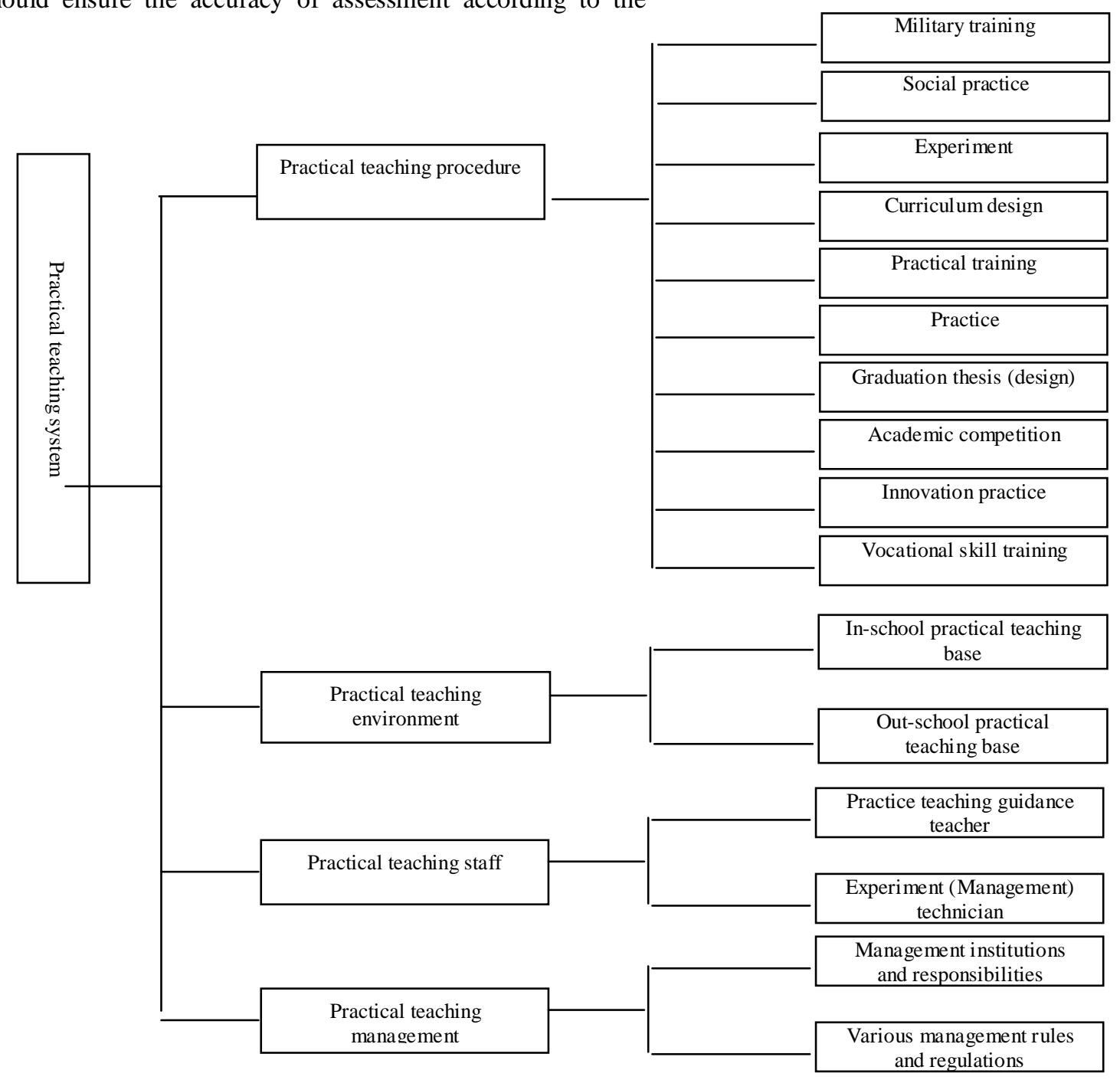

Fig. 4. Practical teaching system

\section{ACKNOWLEDGMENT}

This paper is the funding project of national college students practice base, experimental specialty of undergraduates' engineering education talent cultivation mode reform in general institutes of higher education of Henan Province, project of "specialty comprehensive reform pilot" in Colleges and Universities, research subject of characteristic specialty in Henan Province, research subject of talent cultivation mode reform in Huanghe Science \& Technology College, etc. and regulations 
[5] Yao Zhiqiang, $\mathrm{Pu}$ Wenyu. Thoughts on Engineering Practice in Application-oriented Universities [J]. Journal of Changshu Institute of Technology, the 12th issue, 2010.

[6] Yin Xueming, Jiang Jing. On the Theory of Post Practice Teaching [J]. Journal of Liaocheng University: Social Science Edition, the 5th issue, 2010.

[7] Sheng Jingjun, Wang Qing, Li Xuebai. Increase Practical Teaching and Improve Students' Working Ability [J]. Folk Art and Literature, the 11 th issue, 2010.

[8] Xiong Lin. Discussion on Quality Education in Practice Teaching [J]. Science \& Technology Information, the 35th issue, 2010.

[9] Sun Xiaoyang. Scientific Summary and Experience of Practice Teaching Reform [J]. Journal of Nanchang College of Education, the 6 th issue, 2010. 